УДК 697.9

\title{
To Calculation Heat- and Water Emission at Design of Ventilation in Conveyor Galleries for Transportation of Wet Heated Materials
}

\author{
Ilya V. Kalinich and Gennady V. Smolnikov \\ Siberian Federal University \\ 79 Svobodny, Krasnoyarsk, 660041, Russia
}

Received 27.01.2016, received in revised form 13.03.2016, accepted 21.05.2016

Article is devoted to questions of a heat and mass transfer of wet heated materials at conveyor transportation. Charge material and sinter return of are investigated. The data necessary at design of systems of ventilation in conveyor galleries for transportation of these materials are obtained.

Keywords: emission of water vapour, heat transfer, coefficient of heat transfer, coefficient of heat conductivity, mass transfer coefficient.

Citation: Kalinich I.V., Smolnikov G.V. To calculation heat- and water emission at design of ventilation in conveyor galleries for transportation of wet heated materials, J. Sib. Fed. Univ. Eng. technol., 2016, 9(4), 603-610. DOI: 10.17516/1999-494X-2016-9-4-603-610.

\section{К расчёту тепло- и влаговыделений \\ при проектировании вентиляции \\ в конвейерных галереях \\ для транспортировки влажных \\ нагретых материалов}

И.В. Калинич, Г. В. Смольников

Сибирский федеральный университет

Россия, 660041, Красноярск, пр. Свободный, 79

Статья посвящена вопросам тепломассообмена влажных нагретых материалов при конвейерной транспортировке. Исследованы иихта и возврат агломерата. Получены данные, необходимые при проектировании систем вентиляции в конвейерных галереях для транспортировки данных материалов.

(c) Siberian Federal University. All rights reserved

* Corresponding author E-mail address: il-k@mail.ru, genad123@mail.ru

$$
-603-
$$


Ключевые слова: выделение водяных паров, теплоотдача, коэффициент теплоотдачи, коэффициент теплопроводности, коэффициент массообмена.

На горнообогатительных комбинатах широко распространена конвейерная транспортировка влажных нагретых материалов. При проектировании систем вентиляции конвейерных галерей для транспортировки влажных нагретых материалов возникает необходимость определения количества теплоты и влаги, выделяющихся от поверхности материала в объём помещения. Для этой цели необходимы данные об изменении температуры поверхности материала при его транспортировании.

Суммарные поступления явного тепла от единицы поверхности материала в объем помещения определяются по формуле

$$
q_{\mathrm{s}}=q+q_{\mathrm{T}}
$$

где $q$ - общая теплоотдача материала конвекцией и излучением, Вт; $q_{\mathrm{T}}-$ количество явного тепла, поступающего в воздух за счёт остывания водяных паров, Вт.

Общая теплоотдача материала конвекцией и излучением рассчитывается как

$$
q=\alpha \cdot\left(t_{\mathrm{M}}-t_{\mathrm{B}}\right),
$$

где $\alpha$ - суммарный коэффициент теплообмена, $\mathrm{BT} /\left(\mathrm{M}^{2 * o} \mathrm{C}\right) ; t_{\mathrm{M}}-$ температура материала, ${ }^{\circ} \mathrm{C}$; $t_{\mathrm{B}}$ - температура окружающего воздуха, ${ }^{\circ} \mathrm{C}$.

Количество явного тепла, поступающего в воздух за счёт остывания водяных паров,

$$
q_{\mathrm{T}}=c \cdot m \cdot\left(t_{\mathrm{M}}-t_{\mathrm{B}}\right),
$$

где $c$ - теплоёмкость водяного пара, Дж/(кг*o $\mathrm{C}) ; m$ - интенсивность выделения водяных паров, $\left(\kappa \Gamma^{*} \mathrm{M}^{2}\right) / \mathrm{c}$.

Интенсивность выделения водяных паров при внешнем массообмене подчиняется закону Дальтона:

$$
m=\beta \cdot\left(p_{\mathrm{M}}-\varphi_{\mathrm{B}} \cdot p_{\mathrm{B}}\right),
$$

где $\beta$ - коэффициент массообмена, зависящий от крупности и влажности материала, а также от

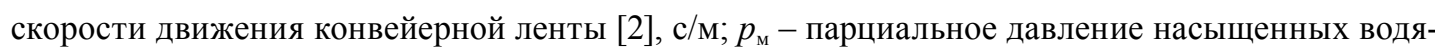
ных паров при температуре поверхности материала, Па; $p_{\text {в }}$ парциальное давление насыщенных водяных паров при температуре воздуха в помещении, Па; $\varphi_{\text {в }}-$ относительная влажность воздуха в помещении, \%.

По характеру тепло- и массообмена участки транспортировки влажных нагретых материалов в конвейерных галереях на горнообогатительных комбинатах можно разделить на две группы.

К первой группе относятся конвейеры с двухслойной укладкой материала. Нижним слоем является влажная шихта, имеющая температуру около $20^{\circ} \mathrm{C}$ и влажность до $16 \%$. Верхний слой состоит из сухого возврата агломерата с температурой $400-800{ }^{\circ} \mathrm{C}$.

Ко второй группе относятся конвейеры с равномерно прогретой до температуры $60-80{ }^{\circ} \mathrm{C}$ шихтой, влажность которой составляет $6-10 \%$.

$$
-604-
$$


Исследованиями авторов в производственных условиях установлено, что при транспортировании материалов второй группы изменение температуры и влажности материала по длине конвейера в пределах одной галереи незначительно. В связи с этим процесс поступления тепла и водяных паров от поверхности материала в объём галереи можно рассматривать как стационарный процесс при постоянной температуре и влажности материала.

При транспортировке материалов первой группы теплоотдача от поверхности в окружающую среду и в слой шихты имеет существенно нестационарный характер, что связано с остыванием поверхности верхнего слоя частиц.

Оценка интенсивности охлаждения возврата агломерата была произведена авторами с использованием закономерностей нестационарной теплопроводности, руководствуясь данными работы [3]. В расчётах приняты следующие допущения:

1) материал состоит из шаров различного диаметра соответственно гранулометрическому составу;

2) охлаждение шаров водяными парами является несущественным.

Процесс нестационарной теплопроводности определяется критериями Био и Фурье:

$$
\begin{gathered}
\mathrm{Bi}=\frac{\alpha \cdot l}{\lambda_{\mathrm{M}}} ; \\
\mathrm{Fo}=\frac{\alpha_{\mathrm{M}} \cdot \tau}{l^{2}},
\end{gathered}
$$

где $\alpha$ - коэффициент теплоотдачи от поверхности шара в окружающую среду, Вт/( $\left.{ }^{2 * o} \mathrm{C}\right)$; $l$ - определяющий размер, за который в рассматриваемом случае принят радиус шара [3], м; $\lambda_{\text {м }}$ коэффициент теплопроводности материала, принятый по данным работы [4] для возврата агломерата, равный $0,65 \mathrm{BT} /\left(\mathrm{M}^{2 * o} \mathrm{C}\right) ; a_{\mathrm{M}}$ - коэффициент температуропроводности возврата агло-

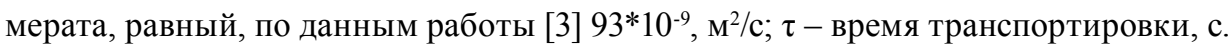

При малых значениях числа Био $(\mathrm{Bi}<1)$ решение дифференциального уравнения теплопроводности для охлаждения шара приводится к виду

$$
\theta_{\tau}=\theta_{0} \cdot \exp \cdot(-3 \cdot \mathrm{Bi} \cdot \mathrm{Fo})
$$

где $\theta_{\tau}-$ избыточная температура поверхности шара в любой момент времени, ${ }^{\circ} \mathrm{C} ; \theta_{0}-$ избыточная температура поверхности шара в начальный времени, ${ }^{\circ} \mathrm{C}$.

Избыточная температура поверхности шара в любой момент времени определяется по формуле

$$
\theta_{\tau}=t_{\tau}-t_{\mathrm{B}}
$$

где $t_{\tau}-$ температура поверхности шара в любой момент времени, ${ }^{\circ} \mathrm{C}$.

Избыточную температуру поверхности шара в начальный момент времени находим по формуле

$$
\theta_{0}=t_{0}-t_{\mathrm{B}},
$$

где $t_{0}-$ температура поверхности шара в начальный момент времени, ${ }^{\circ} \mathrm{C}$.

$$
-605-
$$


В соответствии с уравнениями (5) - (7) интенсивность остывания шаров зависит от их диаметра, поэтому следует рассмотреть остывание отдельных шаров различного диаметра.

Расчёт производили в следующем порядке.

Определяли коэффициент теплоотдачи $\alpha$ как

$$
\alpha=\alpha_{л}+\alpha_{\mathrm{\kappa}},
$$

где $\alpha_{л}-$ коэффициент теплоотдачи излучением, Вт/( $\left.{ }^{2 * o} \mathrm{C}\right) ; \alpha_{\text {к }}$ - коэффициент теплоотдачи конвекцией, Вт/( $\left.{ }^{2 * \circ} \mathrm{C}\right)$.

Коэффициент теплоотдачи излучением, согласно данным работы [5], равен:

$$
\alpha_{\text {л }}=\frac{\varepsilon_{\text {пр }} \cdot c_{0} \cdot\left[\left(\frac{t_{\tau}+273}{100}\right)^{4}+\left(\frac{t_{\mathrm{B}}+273}{100}\right)^{4}\right]}{t_{\mathrm{M}}-t_{\mathrm{B}}},
$$

где $\varepsilon_{\text {пр }}$ - приведённая степень черноты обменивающихся теплом поверхностей, равная для материалов ограждающих конструкций и возврата агломерата 0,$95 ; c_{0}$ - коэффициент излучения абсолютно чёрного тела, равный 5,67 Вт/( $\left.\mathrm{M}^{2 *}{ }^{\circ} \mathrm{C}^{4}\right)$.

При определении коэффициента конвективного теплообмена было принято допущение, что при высоких начальных температурах теплоотдающей поверхности в условиях конвейерной транспортировки преобладает теплоотдача за счёт естественной конвекции,

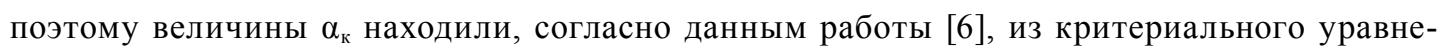
ния

$$
\mathrm{Nu}=0,54 \cdot(\mathrm{Gr} \cdot \operatorname{Pr})^{0,25} \text { при } 500<\mathrm{Gr} \cdot \operatorname{Pr}<2 \cdot 10^{7},
$$

где $\mathrm{Nu}$ - число Нуссельта; $\mathrm{Gr}$ - число Грасгофа; $\mathrm{Pr}$ - число Прандтля;

Число Нуссельта устанавливали как

$$
\mathrm{Nu}=\frac{\alpha \cdot l}{\lambda}
$$

где $l$ - определяющий размер, принятый, согласно данным работы [6]: $l=d$, м; $\lambda$ - коэффициент теплопроводности воздуха, равный $0,026 \mathrm{BT} /\left(\mathrm{M}^{* \circ} \mathrm{C}\right)$.

Число Грасгофа определялось как

$$
\mathrm{Gr}=\frac{g \cdot l^{3} \cdot\left(t_{\tau \mathrm{\tau p}}-t_{\mathrm{B}}\right)}{T_{\mathrm{B}} \cdot v^{2}},
$$

где $g$ - ускорение свободного падения, $g=9,81 \mathrm{M} / \mathrm{c}^{2} ; t_{\text {тср }}$ - средняя температура материала на участке, ${ }^{\circ} \mathrm{C} ; T_{\mathrm{B}}$ - температура окружающего воздуха, К; $v$ - кинематическая вязкость воздуха, $v=15^{*} 10^{-6} \mathrm{M}^{2} / \mathrm{c}$.

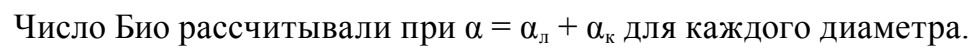

Расчёт выполнялся по участкам, разбитым на длины, соответствующие промежуткам времени транспортировки $\tau$, равным 5, 10 и 20 с. За начальную температуру материала на последнем участке принималась температура в конце предыдущего участка.

$$
-606-
$$


Расчёты проводили для возврата агломерата с начальной температурой $t_{0}=800{ }^{\circ} \mathrm{C}$ и $t_{0}=400{ }^{\circ} \mathrm{C}$ при температуре окружающего воздуха $t_{\mathrm{B}}=15^{\circ} \mathrm{C}$ и $t_{\mathrm{B}}=20^{\circ} \mathrm{C}$.

Как и следовало ожидать, частицы меньшего диаметра остывают более интенсивно. Для них влияние начальной температуры на конечную незначительно при одинаковом времени транспортировки. Температура окружающего воздуха в пределах $t_{\mathrm{B}}=15-20{ }^{\circ} \mathrm{C}$ не оказывает влияния на конечную температуру поверхности частиц.

Для дальнейших расчётов необходимо произвести усреднение температуры по поверхности слоя возврата агломерата. Допустим, что распределение частиц по поверхности слоя возврата такое же, как и в массиве, и для усреднения температуры используем формулу

$$
\sum_{\mathrm{i}=1}^{\mathrm{n}} t_{\mathrm{M}, \mathrm{i}} \cdot F_{\mathrm{i}}=t_{\mathrm{M}, \mathrm{cp}} \cdot \sum_{\mathrm{i}=1}^{\mathrm{n}} F_{\mathrm{i}}
$$

где $F_{\mathrm{i}}$ - площадь поверхности частиц размером $d_{\mathrm{i}}, \mathrm{M}^{2} ; t_{\mathrm{M}, \mathrm{i}}-$ температура поверхности частиц размером $d_{\mathrm{i}},{ }^{\circ} \mathrm{C} ; t_{\mathrm{m}, \mathrm{cp}}-$ средняя по поверхности температура частиц, ${ }^{\circ} \mathrm{C}$.

Используя соотношения

$$
F_{\mathrm{i}} \sim d_{\mathrm{i}}^{2} \cdot n_{\mathrm{i}}
$$

и

$$
n_{\mathrm{i}} \sim \frac{M_{\mathrm{i}}}{\rho \cdot d_{\mathrm{i}}}=\frac{N_{\mathrm{i}}}{\rho} \cdot \frac{M}{d_{\mathrm{i}}^{2}},
$$

получим

$$
F_{\mathrm{i}} \sim \frac{N_{\mathrm{i}}}{d_{\mathrm{i}}} \cdot \frac{M}{\rho},
$$

где $n_{\mathrm{i}}$ - количество частиц размером $d_{\mathrm{i}} ; M_{\mathrm{i}}$ - масса частиц размером $d_{\mathrm{i}}$, кг; $M$ - масса всего возврата агломерата, кг; $N_{\mathrm{i}}$ - массовая доля частиц размером $d_{\mathrm{i}} ; \rho$ - плотность возврата агломерата, кг/м³.

Подставим (18) в (15):

$$
t_{\mathrm{M}, \mathrm{cp}}=\frac{\left(\sum_{\mathrm{i}=1}^{\mathrm{n}} t_{\mathrm{M}, \mathrm{i}} \cdot N_{\mathrm{i}}\right) / d_{\mathrm{i}}}{\left(\sum_{\mathrm{i}=1}^{\mathrm{n}} N_{\mathrm{i}}\right) / d_{\mathrm{i}}} .
$$

Усреднение температуры проводили для следующего гранулометрического состава возврата [2], приведённого в табл. 1

Изменение средней температуры поверхности возврата агломерата по длине конвейера приведено на рис. 1. Наибольшее различие в темпах остывания характерно лишь для начальных участков транспортировки, поэтому на этих участках будут более интенсивные тепловыделения.

Полученная зависимость температуры поверхности возврата агломерата от времени транспортировки позволяет определить по формуле (2) количество тепла, поступающего в помеще-

$$
-607-
$$


Таблица 1. Гранулометрический состав возврата агломерата

\begin{tabular}{|l|c|c|c|c|c|c|}
\hline Класс крупности частиц, мм & $20-10$ & $10-5$ & $5-2,5$ & $2,5-1,25$ & $1,25-0,63$ & $0,63-0$ \\
\hline Средняя крупность частиц $d_{\mathrm{i}}$, мм & 15 & 7,5 & 3,76 & 1,83 & 0,94 & 0,32 \\
\hline Массовое содержание частиц $N_{\mathrm{i}}, \%$ & 2 & 31 & 25 & 24 & 8 & 10 \\
\hline
\end{tabular}

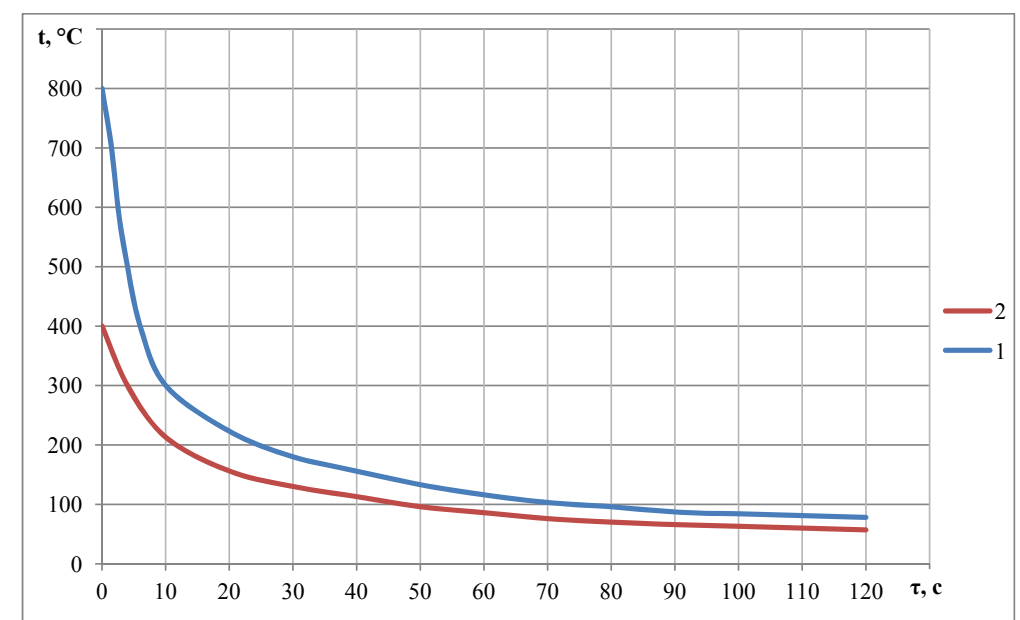

Рис. 1. Изменение температуры поверхности возврата агломерата при конвейерной транспортировке: 1 - при начальной температуре возврата агломерата $800{ }^{\circ} \mathrm{C} ; 2$ - при начальной температуре возврата агломерата $400^{\circ} \mathrm{C}$

ние. При этом тракт транспортировки материала делится на участки, на которых изменение температуры материала сравнительно невелико, определяется средняя температура материала на участке и количество тепла, поступающего в помещение на данном участке.

Согласно зависимости (4) для определения интенсивности влаговыделений от конвейера

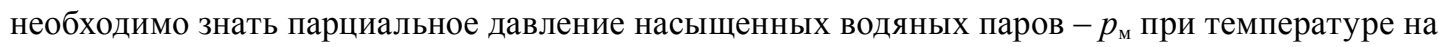
границе слоёв шихты и возврата агломерата $-t_{\text {гр }}$.

Оценим температуру на границе слоёв исходя из условия равенства подводимого и отводимого тепла:

$$
\frac{t_{\mathrm{M}, \mathrm{cp}}-t_{\mathrm{rp}}}{R_{\mathrm{a}}}=\frac{t_{\mathrm{rp}}-t_{\mathrm{m}}}{R_{\mathrm{m}}},
$$

где $R_{\mathrm{m}}$ - термическое сопротивление слоя шихты, $\mathrm{BT} / \mathrm{M}^{2} ; R_{\mathrm{a}}$ - термическое сопротивление слоя возврата агломерата, Вт/ $/ \mathrm{M}^{2} ; t_{\text {шI }}$ - температура шихты на ленте конвейера, ${ }^{\circ} \mathrm{C}$.

Термическое сопротивление слоя шихты определяется по формуле

$$
R_{\mathrm{w}}=\frac{\delta_{\mathrm{II}}}{\lambda_{\mathrm{II}}},
$$

где $\delta_{\text {ш }}-$ толщина слоя шихты, м; $\delta_{\text {ш }}=0,16$ м; $\lambda_{\text {ш }}-$ коэффициент теплопроводности шихты, $\mathrm{BT} / \mathrm{M}^{* \circ} \mathrm{C} ; \lambda_{\mathrm{II}}=1,54 \mathrm{BT} / \mathrm{M}^{* \circ} \mathrm{C}$. 


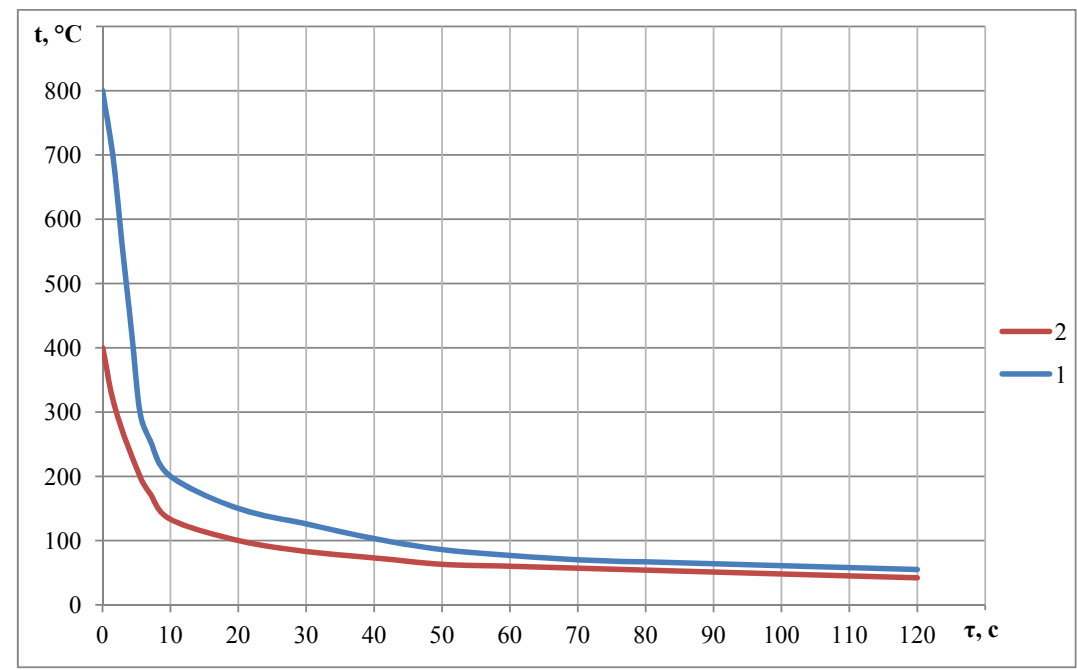

Рис. 2. Изменение температуры поверхности слоя шихты при конвейерной транспортировке: $1-$ при начальной температуре верхнего слоя $800{ }^{\circ} \mathrm{C} ; 2$ - при начальной температуре верхнего слоя $400{ }^{\circ} \mathrm{C}$

Термическое сопротивление слоя возврата агломерата можно вычислить по формуле

$$
R_{\mathrm{a}}=\frac{\delta_{\mathrm{a}}}{\lambda_{\mathrm{M}}}
$$

где $\delta_{\mathrm{a}}$ - толщина слоя возврата агломерата, м; $\delta_{\mathrm{a}}=0,04 \mathrm{~m} ; \lambda_{\mathrm{m}}-$ коэффициент теплопроводности возврата агломерата, $\mathrm{BT} / \mathrm{M}^{* \circ} \mathrm{C} ; \lambda_{\mathrm{M}}=0,65 \mathrm{BT} / \mathrm{M}^{*{ }^{\circ}} \mathrm{C}$.

Исходные данные для $\delta_{\text {шा }} ; \delta_{\mathrm{a}} ; \lambda_{\text {шा }} ; \lambda_{\mathrm{M}}$ приняты согласно работе [4].

Решение уравнения (20) с использованием данных о распределении температуры возврата агломерата по длине конвейера (рис. 1) позволило получить изменение температуры поверхности слоя шихты по длине конвейера (рис. 2).

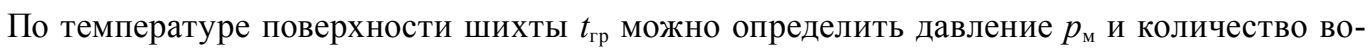
дяных паров, поступающих в помещение. При этом на участках конвейера, где температура шихты выше температуры кипения при данном барометрическом давлении, величину парциального давления насыщенных водяных паров $p_{м}$ в формуле (4) следует принимать равной величине барометрического давления $p_{\mathrm{a}}$. На участках, где температура шихты ниже температу-

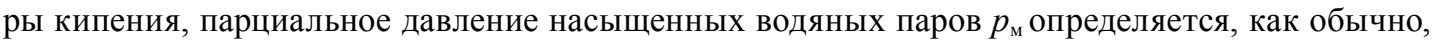
в зависимости от температуры.

Поученные данные об изменении температур поверхности возврата агломерата и шихты по длине конвейера могут быть использованы для расчёта тепло- и влаговыделений от поверхности транспортируемого материала при проектировании вентиляции конвейерных галерей для транспортировки влажных нагретых материалов.

\section{Список литературы}

[1] Шумилов Р. Н. Расчёт влаговыделений при транспортировке зернистых материалов конвейерами. Водоснабжение и санитарная техника. 1968, 3(8), 30-31 [Shumilov R. N. Calculation

$$
-609-
$$


of Moisture Allocations When Transporting Granular Materials by Conveyors, Water Supply and Sanitary Equipment, 1968, 3(8), 30-31 (in Russian)]

[2] Афанасьев И. И., Ващенко В. С., Генералов Г. С. Обеспьливание воздуха на фабриках горнообогатительных комбинатов. М.: Недра, 1972. 184 с. [Afanas'ev I. I., Vashhenko V. S., Generalov G. S. Obespylivanie vozduha na fabrikah gornoobogatitel'nyh kombinatov. Moscow, Nedra, 1972, 184 p. (in Russian)]

[3] Шорин С. Н. Теплопередача. М.: Высшая школа, 1964. 490 с. [Shorin S. N. Teploperedacha. Moscow, Vysshaja shkola, 1954, 490 p. (in Russian)]

[4] Марииченко В. М. Электромоделирование нестационарного теплообмена между шихтой и возвратом агломерата при конвейерном транспортировании. В кн.: Охрана труда и техника безопасности в горнорудной промышленности. М.: Недра, 1978. 69 с. [Mariichenko V. M. Jelektromodelirovanie nestacionarnogo teploobmena mezhdu shihtoj i vozvratom aglomerata pri konvejernom transportirovanii. V kn.: Ohrana truda i tehnika bezopasnosti v gornorudnoj promyshlennosti. Moscow, Nedra, 1978, 69 p. (in Russian)]

[5] Исаченко В. П., Осипова В. А., Сукомел А. С. Теплопередача. М.: Энергия, 1981. 416 с. [Isachenko V. P., Osipova V. A., Sukomel A. S. Teploperedacha. Moscow, Jenergija, 1981, 416 p. (in Russian)]

[6] Лыков А. В. Теоретические основы строительной теплофизики. Минск: Издательство АН БССР, 1961. 520 c. [Lykov A. V. Teoreticheskie osnovy stroitel'noj teplofiziki. Minsk: Izdatel'stvo AN BSSR, 1961, 520 p. (in Russian)] 